\title{
Una mirada materialista sobre los debates epistemológicos en la psicología social ${ }^{*}$
}

\section{A materialist look about epistemological debates in social psychology}

\section{José Enrique Ema López** \\ Centro de Estudios Universitarios de \\ Talavera de la Reina \\ Universidad de Castilla-La Mancha, \\ España}

Recibido: 2 de diciembre de 2008

Revisado: 15 de febrero de 2009

Aceptado: 19 de mayo de 2009

\section{Resumen}

Este artículo desarrolla un punto de vista materialista en el terreno de los debates epistemológicos introducidos en la psicología y en la psicología social por el Construccionismo Social (no es posible pensar hoy sobre la epistemología en este campo sin pasar por sus aportaciones). Para ello se expone, en primer lugar, las interrogaciones críticas más relevantes introducidas por esta perspectiva. Después se dialogará con ellas al mostrar una propuesta a partir de algunos puntos de tensión con el Construccionismo Social. Finalmente, a modo de conclusión, se destacan las implicaciones éticas y políticas sobre los dos elementos planteados - sujeto-agente y objetividad situada-.

Palabras clave: Epistemología, Construccionismo Social, materialismo.

Artículo de investigación documental.

Correspondencia: José Enrique Ema López, Profesor de la Universidad de Castilla-La Mancha. Avda. Real Fábrica de Sedas, s/n 45600 - Talavera de la Reina, Toledo, España. Correo electrónico: JoseEnrique.Ema@uclm.es. 


\begin{abstract}
In this paper we develop a material point of view in terms of epistemological debates introduced in psychology and in social psychology by social constructionism (it's impossible today think about epistemology without going through their contributions). First, we show the most relevant critical questions done by this prospect. After we show our proposal on some points of tension with the social constructionism. Finally we emphasize the ethical and political implications of our materialistic point of view.
\end{abstract}

Keywords: epistemology, Social Constructionism, materialism.

\section{Introducción}

La promesa emancipadora derivada de la llustración ha sido alimentada por una concepción objetivo-positivista del conocimiento científico que se ha desarrollado hegemónicamente en las ciencias sociales, mediante una idea de objetividad como correspondencia (de nuestras representaciones) con la realidad. Desprovisto así de cualquier "sesgo" subjetivo, el conocimiento científico se relacionaría paradójicamente con nuestras posibilidades de transformación emancipadora. La paradoja radica en que la dimensión ética de esta promesa de emancipación se vincula con un tipo de conocimiento científico -objetivo-positivistay de un saber técnico-instrumental derivado de éste, cuando precisamente, la ética y la política no pueden ser tales si encuentran un fundamento previo a la apertura de una posición subjetiva de responsabilidad (aunque ésta sólo pueda ser parcial y limitada, como veremos).

Si nuestras propuestas éticas y políticas contaran con ese fundamento (una realidad positiva "ahí fuera", un conocimiento científico capaz de representarla fielmente y una técnica de intervención deducida necesariamente de este conocimiento) sólo tendríamos fórmulas que ejecutar sin margen alguno para una decisión ético-política. Así, el sujeto únicamente debería leer y obedecer las leyes escritas del mundo, situándose por debajo de la Ley (científica o natural) como su resultado o consecuencia. Pero tampoco del lado de un sujeto trascendental y omnipotente (por encima de la Ley) podría venir la viabilidad de la ética y de la política. Esta posición sería igualmente determinista, aunque en el sentido inverso, ocuparíamos el lugar de Dios, en donde no hay decisión ética posible, sino un saber absoluto y autoproducido.

Y es que la experiencia ética sólo puede existir a partir de la confrontación del sujeto con la misma imposibilidad de una ley definitiva (científica, natural, divina), tal y como afirma Giorgio Agamben:

el hombre (sic) no es, ni ha de ser o realizar ninguna esencia, ninguna vocación histórica o espiritual, ningún destino biológico. Sólo por esto puede existir algo así como una ética: pues está claro que si el hombre fuese o tuviese que ser esta o aquella sustancia, este o aquel destino, no existiría experiencia ética posible, y sólo habría tareas que realizar. Esto no significa, todavía, que el hombre no sea ni tenga que ser alguna cosa... Hay, de hecho, alguna cosa que el hombre es y tiene que pensar, pero esto no es una esencia, ni es tampoco propiamente una cosa: es el simple hecho de la propia existencia como posibilidad y potencia. Pero justo por esto todo se complica, justo por esto la ética llega a ser efectiva (1996, p. 31).

Resulta necesario, entonces, reconocer como condición para la ética y la política un espacio de contingencia y apertura inerradicable en la experiencia humana. Sin embargo, hoy en día el discurso sobre lo humano de la ciencia y el saber técnico se levantan sobre el ideal de la clausura de esta brecha necesaria entre conocimiento y acción ética y política. Así, asistimos a la homogeneización, finalmente autoritaria, del conocimiento bajo el revestimiento de un saber técnico-científico ofrecido como promesa de 
compresión absoluta y definitiva ${ }^{1}$. De este modo, nos encontramos con una estrecha vinculación entre el orden hegemónico establecido (el capitalismo global contemporáneo) y un saber científico despolitizador que considera como inviable cualquier formulación ético-política que escape de los posibles ya naturalizados como "obvios" (las "leyes" del mercado, la bondad de la lógica de la cuantificación y el beneficio económico, la individualización de los malestares culturales y las desigualdades sociales, etc.).

En la psicología social, el Construccionismo Social (en adelante CS) se ha enfrentado a estos efectos autoritarios de la ciencia -y especialmente de la psicología - fundamentalmente a partir del cuestionamiento de la epistemología objetivista y positivista predominante en esta disciplina. Sin embargo, a partir de sus críticas nos hemos encontrado con la dificultad de sostener (epistemológicamente) cualquier tipo de noción de objetividad -no sólo aquellas que se levantaban sobre una concepción positivista, sino de cualquier otra forma de objetividad/verdad parcial y situada-. Y tal y como afirma Donna Haraway en relación con su propuesta de "conocimientos situados", nos parecen necesarios, frente a las totalizaciones del "objetivismo desencarnado" y del "relativismo ingenuo", conocimientos que permitan:

una versión del mundo más adecuada, rica y mejor, con vistas a vivir bien en él y en relación crítica y reflexiva con nuestras prácticas de dominación y con las de otros y con las partes desiguales de privilegio y de opresión que configuran todas las posiciones (Haraway, 1995, p. 321).

La posibilidad misma de las prácticas emancipadoras depende del modo como vinculemos nuestras concepciones sobre el conocimiento (epistemología) y el sujeto, y también sobre la naturaleza de los objetos del mundo (ontología). Se trataría de hacer viables dos elementos. El primero: un sujeto capaz para la ética, es decir, un sujeto agen-

1 Aunque muchas de las cuestiones que presentamos en este trabajo se pueden aplicar a lo que se han denominando como ciencias naturales, nuestras reflexiones se refieren específicamente a las ciencias humanas-sociales (iy a las médicas!) en tanto que dispositivos tecnocientíficos que tratan de explicar el funcionamiento de lo humano. te -o con agencia- (Ema, 2004) y responsable, ni por encima, ni por debajo de la Ley. El segundo: la posibilidad/necesidad práctica de acceder a versiones de la realidad "más adecuadas", a alguna noción objetiva. En nuestra opinión, es necesario mantener ambas cuestiones entrelazadas bajo una concepción ontológica materialista que, alejada de cualquier pretensión idealista y metafísica, asuma la imposibilidad de un discurso de plenitud para la existencia humana.

Este trabajo está dedicado a desarrollar y argumentar este punto de vista materialista en el terreno de los debates epistemológicos introducidos en la psicología y en la psicología social por el CS (no es posible pensar hoy sobre la epistemología en este campo sin pasar por sus aportaciones). Para ello expondremos, en primer lugar, las interrogaciones críticas más relevantes introducidas por esta perspectiva. Después, dialogaremos con ellas mostrando nuestra propuesta a partir de algunos puntos de tensión con el CS. Finalmente, a modo de conclusión, destacaremos las implicaciones éticas y políticas de nuestro punto de vista sobre los dos elementos planteados - sujetoagente y objetividad situada-.

\section{La propuesta epistemológica y ontológica del Construccionismo Social}

El nacimiento del $\mathrm{CS}^{2}$ está vinculado al autor norteamericano Kenneth J. Gergen. Desde la aparición de su artículo en 1985: The Social Constructionist Movement in Modern Psychology el "movimiento" socioconstruccionista se ha ido constituyendo dentro de la psicología social como una estimulante propuesta crítica. Desde sus inicios, ha mantenido una clara preocupación ética y política frente a los efectos normativizadores y autoritarios atribuidos a la psicología.

2 Para esta breve presentación del Construccionismo Social tomamos como referencia fundamentalmente los trabajos de Kenneth J. Gergen y Tomás Ibáñez aunque hay una amplísima red de autores y autoras relevantes que pueden ser adscritos a esta perspectiva y que lógicamente presentan matices y diferencias importantes que impiden hablar de un enfoque homogéneo. 
El CS aborda las relaciones que se establecen entre el conocimiento y la realidad en un contexto de cuestionamiento de algunos presupuestos sobre el conocimiento científico de los fenómenos psicosociales (epistemología), la propia naturaleza de estos fenómenos (ontología) y las relaciones entre epistemología y ontología a partir de sus implicaciones ético-políticas. Así, el CS introduce algunos de los debates "postmodernos" que ya estaban produciéndose en otras disciplinas y que afectan a lo que Gonzalo Abril (1999) denomina como las dos dimensiones complementarias de la ley social: la legibilidad y la legitimidad; es decir, por una parte, la posibilidad misma del conocimiento y la producción de sentido, y por otra, su dimensión ético-normativa. De este modo se anudaban también en la psicología y en la psicología social diferentes cuestionamientos hacia la herencia moderna e ilustrada que ha sostenido (y sostiene) la propia posibilidad de una actividad humana emancipadora.

\section{Epistemología}

El CS cuestiona el trasfondo de presupuestos epistemológicos hegemónicos en la psicología contemporánea a los que vincula con la producción de un conocimiento autoritario y normativizador. De este modo se volvería imprescindible deshacerse de estos presupuestos para hacer de la psicología una herramienta liberadora y no un dispositivo de control (Ibáñez, 2001).

Así, el socioconstruccionismo, en deuda con el "giro lingüístico", critica la creencia de que los seres humanos podemos producir un lenguaje que refleje o represente la realidad "tal cual es". Esta crítica cuestiona radicalmente la concepción objetivista y positivista del conocimiento como representación (de la realidad) al considerar al propio conocimiento como una práctica constructora de su objeto. Tal y como afirma Ibáñez:

Cuando elaboramos un conocimiento no estamos representando algo que estaría ahí fuera en la realidad, como tampoco estamos traduciendo esos objetos exteriores en ecuaciones y en enunciados, estamos construyendo de par en par un objeto original que no traduce nada y que no representa ningún trozo de realidad con el cual estaría en correspondencia (1994, p. 248).

Para una posición objetivo-positivista se podría definir el grado de verdad de las representaciones que constituyen nuestro conocimiento contrastándolas con la realidad misma. El criterio de legitimidad -de verdad- del conocimiento sería, por tanto, el de su correspondencia con la realidad. Sin embargo, este punto de vista puede ser rebatido al constatar que no podemos acceder directamente -sin mediación de alguna forma de representación- a la realidad misma "tal cual es" para comparar ésta con nuestras representaciones y ver así si "se corresponden" con aquella (Rorty, 1979).

Aunque los argumentos que se pueden utilizar para impugnar esta creencia representacionista son diversos y provienen de distintos ámbitos - desde las críticas ideológicas desarrolladas en torno a la Escuela de Frankfurt, pasando por las del posestructuralismo francés, hasta las críticas sociales de la sociología del conocimiento (Gergen, 1996, 1999)- quizá el elemento más relevante para caracterizar la propuesta epistemológica socioconstruccionista es el reconocimiento de la imposibilidad de un conocimiento libre de marcas sociales, es decir, de condiciones sociales de enunciación. Para el CS, el significado es un producto social. Así, se formula una teoría de la producción de conocimiento como construcción social y discursiva que pone de manifiesto cómo el significado de las palabras no tiene su origen en su correspondencia con un objeto que está "ahí fuera" en el mundo, sino que éste deriva de su participación en un juego de sedimentaciones y regularidades sociales (códigos, normas), que no están ahí con independencia de la participación humana. Los significados son dependientes de estas regularidades sedimentadas que hacen posible cualquier práctica de producción de sentido. La propuesta socioconstruccionista muestra, por tanto, que el conocimiento no está determinado por los objetos, sino que se constituye en una red de prácticas sociales y lingüísticas convencionales, social e históricamente situadas en una tradición cultural (Gergen, 1996). 
Así, desde el CS se critica radicalmente el supuesto que sostiene que la realidad existe "tal cual es" con independencia de las prácticas y el conocimiento de los seres humanos. Los mismos procesos de conocimiento que median entre nosotros y lo que denominamos como realidad, intervienen constitutivamente en el estatus mismo que adquiere la realidad. Lo que tomamos como objetos naturales en nuestras vidas cotidianas no son sino objetivaciones que resultan de nuestras convenciones y de nuestras prácticas lingüísticas (lbáñez, 1996).

De este modo, el CS vincula el punto de vista objetivo-positivista con efectos autoritarios. En la medida que consideramos que la realidad "habla por sí misma" y los hechos "son como son", con independencia de nuestro modo (social) de acceder a ellos, invisibilizamos las relaciones humanas (de poder) que están en la base de cualquier efecto de objetivación y naturalización del mundo. Así, en nombre de la objetividad, asumimos como necesarios y esencialmente incontrovertibles fenómenos que son contingentes y modificables. Desde este punto de vista reconocer el carácter construido de la realidad sería una condición necesaria para cualquier propuesta de cambio liberadora y emancipadora.

\section{Ontología}

La propuesta epistemológica socioconstruccionista tiene implicaciones ontológicas, es decir, mantiene una determinada concepción implícita sobre lo que son los objetos del mundo (construidos, dependientes del conocimiento, etc.). Afirmar que el conocimiento, más que representar, construye, supone reconocer que, en alguna medida, algo de lo que el objeto es, es producido por la misma práctica de conocimiento. Así, conocer la realidad, es hacer realidad. Al destacar el carácter instituyente de nuestro conocimiento, el CS desarrolla a través de éste una explicación ontológica de los contenidos de la realidad en tanto que es producto humano. Sin embargo, las propuestas construccionistas renuncian a elaborar una propuesta ontológica explícita para evitar cualquier posible mirada sustancialista metafísica que reintrodujera como fundamento último del conocimiento una supuesta naturaleza esencial y positiva ("ahí dada") de los objetos del mundo. Explícitamente la ontología se convierte en algo sobre lo que no se puede, ni se debe decir nada. De este modo, el CS se constituye como ontológicamente mudo y desplaza y subordina cualquier tipo de preocupación ontológica al terreno de la epistemología. En palabras de Gergen:

El construccionismo no niega que haya explosiones, pobreza, muerte, o, de un modo más general, el 'mundo ahí fuera'. Tampoco hace ninguna afirmación. Tal como indiqué, el construccionismo es ontológicamente mudo. Cualquier cosa que sea, simplemente es. No hay descripción fundacional que hacer sobre un 'ahí fuera' como algo opuesto a 'aquí dentro', sobre la experiencia o lo material (1996, p. 98).

No se afirma que los hechos sociales no existan, sino que se renuncia a la posibilidad de formular cualquier tipo de lectura sobre la naturaleza de las cosas. Al poner en el lugar de la ontología a la epistemología no podemos hablar "directamente" de los objetos del mundo, sino sólo de nuestro modo de referirnos a ellos. Por eso, Gergen argumenta a favor de la duda del estatus de realidad del mundo que está "ahí fuera" desde la consideración de que la realidad es dependiente de las operaciones y procesos que posibilitan su conocimiento. El anti-esencialismo del CS se convierte así en anti-ontología.

\section{Algunos cuestionamientos y puntos de tensión con el Construccionismo Social (CS)}

El CS se mueve entre dos opciones que construye como antagónicas: o silenciamos cualquier preocupación ontológica a partir de la constatación de que nuestra realidad está constituida por nuestras prácticas sociales (de conocimiento) o reintroducimos una mirada ontológica esencialista metafísica de la que se derivaría una propuesta epistemológica objetivo-positivista. Nuestra posición, que comparte la crítica "antiautoritaria" a la concepción objetivo-positivista del conocimiento, se distancia de esta obligación 
al silencio ontológico. En la base de la propuesta del CS estaría presente el binarismo ontológico característico de la Modernidad que modela el mundo bajo la forma de parejas de elementos opuestos (social vs. natural, cultural vs. biológico, simbólico vs. material, sujeto vs. objeto, mente vs. cuerpo, etc.). Y, desde nuestro punto de vista, estos presupuestos ontológicos nos sitúan ante algunas dificultades para la transformación emancipadora. Veamos esta cuestión con más detalle.

En las últimas décadas ha aparecido un conjunto de trabajos que han dirigido sus cuestionamientos a la modelización ontológica binaria de la Modernidad. Ésta supuso la constitución de una posición universal dominante alrededor de un ideal de sujeto humano autónomo - sin la dependencia heterónoma de Dios o la Naturaleza-, transparente -capaz de un conocimiento que lo sabe todo sobre sí, sin desconocimiento-, y actor principal en el mundo. Así, este sujeto ideal se constituía a partir del privilegio del primer elemento de cada dicotomía (simbólico, subjetivo, mental,...) frente a "lo otro" que quedaba (del lado del segundo elemento), caracterizado como mudo, pasivo, salvaje, etc. Así, "lo otro" (la naturaleza, las mujeres, lo indígena debería ser dominado, civilizado y domesticado. Sin embargo, al menos con mayor preeminencia durante el siglo $\mathrm{XX}$, asistimos a lo que podríamos denominar como la rebelión de los otros en la que lo que se había situado en los segundos polos de las anteriores dicotomías reclaman con voz propia una modificación del orden jerárquico que ellas instauraban. De este modo se cuestiona el carácter universal del sujeto moderno al mostrar que éste es un particular muy concreto (hombre, blanco, occidental, heterosexual...) expandido a ese lugar universal, $y$, finalmente, un ideal normativo vehículo de relaciones de dominación.

Pero también desde diferentes enfoques ${ }^{3}$ articulados con esta "rebelión", se ha puesto a nuestra disposición un vocabulario teórico para subvertir esta mirada ontológica binaria. Desde estas posiciones podemos cuestionar también al CS por

3 Por ejemplo: los estudios sociales de la ciencia y la tecnología (especialmente la Teoría del Actor-Red) Feminismos, Estudios Poscoloniales o incluso el Psicoanálisis. seguir manteniendo un punto de vista ontológico binario derivado, no del hecho de esencializar los objetos, lo natural, lo material, etc., sino de hacerlo con el otro polo de las dicotomías: lo social, lo cultural, lo simbólico, discursivo, etc. (y todo ello precisamente para mostrar el carácter construido de los objetos, la naturaleza, etc.). Así, el CS ha sido criticado precisamente por priorizar lo subjetivo, discursivo y simbólico, desatendiendo a lo corporal, lo material, lo afectivo-emocional (Pujol, Montenegro, Balasch, 2003; Pujal, 2003).

Ejemplificamos brevemente esta cuestión en relación con la distinción social vs. natural ${ }^{4}$. Las posiciones socioconstruccionistas han puesto de manifiesto que lo social construye lo natural considerando a lo social-humano como un punto de partida no construido. La naturaleza no participa de ningún modo en la construcción de lo social humano, salvo como un testigo pasivo y silencioso. Si para las concepciones científicas tradicionales era la naturaleza la que determinaría el contenido del conocimiento, para el CS, tanto lo natural como lo social son dependientes de lo social. Ambas visiones separan lo social-humano de lo natural-no humano, manteniendo de este modo una brecha entre el sujeto y la realidad. Pareciera que el origen del mundo estaría exclusivamente del lado de las prácticas sociales construidas por los seres humanos. Las siguientes palabras ejemplifican lo que queremos señalar:

...somos nosotros quienes instituimos como objetos los objetos de los que aparentemente está hecha la realidad. El objeto no genera nuestra representación de él sino que resulta de las prácticas que articulamos para representarlo (Ibáñez, 1996, p. 330).

Pero si nosotros instauramos unidireccionalmente el mundo, nuestras prácticas de construcción del mundo aparecen como independientes y separadas de éste. Así, el CS que cuestiona la existencia del mundo independiente de lo humano, no logra superar esta brecha al sacar ahora a lo humano del mundo convirtiéndolo en su constructor cuasiomnipotente. De este modo se mantiene el mismo

4 Recogemos aquí las críticas de Bruno Latour $(1992,1993)$ al punto de vista socioconstruccionista en los Estudios Sociales de la Ciencia. 
dualismo sujeto-objeto que se ha disuelto en una dirección (los objetos del mundo dentro de lo humano) para bifurcarse en otra (lo humano fuera del mundo de los objetos) (Ema, García Dauder \& Sandoval, 2003).

También, en relación con el sujeto, el CS seguiría instalado en esta mirada binaria, participando en ella a partir del enfrentamiento entre objetivismo y subjetivismo que ha acompañado desde sus inicios a las ciencias sociales (aunque su posición es más fina y matizada que la que se reduciría a la elección de uno de estos polos). Así, el CS sostiene la paradoja de "autonomizar" al sujeto separándolo del mundo como su constructor cuasi-omnipotente y simultáneamente hacerlo desaparecer como producto de las condiciones sociales. En relación con el sujeto epistémico -al sujeto que conoce o que es capaz de conocer- su posición se desplazaría hacia el polo subjetivista (Sandoval, 2004) -entendiendo éste en su dimensión antropocéntrica y humanista-. El sujeto que construye el mundo aparece fuera de él, es decir, no construido por él. Implícitamente, si el sujeto constituye el mundo, se reintroduce esta dimensión de cuasi-omnipotencia de lo humano que desde una posición de exterioridad es capaz de hacerlo emerger.

Sin embargo, el CS participa también de la deconstrucción del ideal de un sujeto individual autónomo, origen y fuente única del significado del mundo al atender especialmente a su dimensión social y relacional y cuando muestra su dependencia histórica y contextual de la trama de relaciones sociales que lo constituyen. No en vano trata de enfrentarse al reduccionismo psicologicista e individualista que constituye al sujetoindividuo $\mathrm{y} / \mathrm{o}$ sus características psicológicas, o psicopatológicas, como destino y origen de todo lo que acontece. De este modo, la psicología se convertiría en aliada necesaria del orden establecido para evitar cualquier tipo de explicación en términos sociales, colectivos o políticos que puedan cuestionarlo.

Esta desconstrucción del ideal de un sujeto autónomo y transparente ha permitido desmontar alguno de los lugares comunes psicologicistas e individualistas que sostienen la atribución individual de responsabilidades "morales" estimulando, por el contrario, la crítica de las condiciones sociales y políticas. Así por ejemplo, frente a la descalificación moral que puede recibir una persona que ha cometido un delito, el punto de vista socioconstruccionista puede permitirnos desplazar la responsabilidad más allá del propio individuo ("no le culpabilicemos a él", "han sido las condiciones sociales y políticas de desigualdad en las que vive", "es una víctima de condiciones sociales injustas"). Sin embargo, esta posición tiene un reverso (¿negativo?) que podemos ejemplificar con alguna de las noticias sobre demandas judiciales en Estados Unidos, que de vez en cuando aparecen en los medios de comunicación, por ejemplo, aquella en la que una persona con más de 120 kilos de peso y dificultades cardiovasculares graves relacionadas con la dieta, denuncia a las principales empresas de comida rápida por no haberle informado de los riesgos que corría al consumir con frecuencia sus productos. Aquí podríamos reconocer un mensaje ¿no-psicologicista? del que se podrían derivar algunas conclusiones éticas. Efectivamente, el sujeto (y sus prácticas) aparece como un efecto de las condiciones sociales (por ejemplo, de la publicidad de las empresas de comida rápida) pero también aparece finalmente pasivo, victimizado y desprovisto de toda capacidad de responsabilidad sobre sus actos, de la posibilidad de hacerse cargo de sus condiciones sociales y transformarlas. Nuevamente nos vemos obligados a elegir: o la responsabilidad se encuentra completamente del lado del sujeto o del de sus condiciones sociales.

Las contradicciones que se derivan de la mirada ontológica binaria que hemos presentado (el sujeto omnipotente que construye al mundo frente al sujeto resultado de sus condiciones sociales) se muestran ahora con toda claridad como cuestión ética y política: nos encontramos con un sujeto que es, o bien, absolutamente capaz y responsable de todo lo que acontece $(\mathrm{y}$, que por tanto invisibiliza cualquier tipo de explicación sobre sus acciones en términos sociopolíticos) o bien, ante un sujeto pasivo sin capacidad de acción responsable. 
El compromiso emancipador del CS se ve limitado a partir de sus presupuestos ontológicos binarios implícitos. La limitación que hemos mostrado se refiere a la misma posibilidad de un sujetoagente responsable, puesto que la posición socioconstruccionista nos sitúa ante dos opciones igualmente inviables (sujeto omnipotente vs. sujeto pasivo, víctima de las condiciones sociales). Pero además, estos presupuestos ontológicos (en función de su íntima conexión con aspectos epistemológicos) nos confrontan con otra limitación para la tarea emancipatoria. Nos referimos a la misma posibilidad de conocimiento que nos permita decir y hacer algo que consideramos (éticamente) mejor. Veamos esta segunda cuestión.

Si para el CS no podemos hablar de la naturaleza de los objetos del mundo sino del modo de conocerlos/construirlos, las herramientas políticas transformadoras se desplazan únicamente hacia el lado de la deconstrucción de las objetividades dadas, mostrando el carácter construido y no natural de los procesos de conocimiento implicados $y$, por tanto, del mismo objeto. Pero, en este punto, nos encontraríamos con la dificultad de legitimar y/o proponer otros mundos posibles alternativos a aquellos que se deconstruyen. De acuerdo a la pregunta planteada por Vivian Burr “¿Cómo podemos decir, por ejemplo, que ciertos grupos están oprimidos, si estos grupos y su opresión son construcciones que no pueden ser consideradas más verdaderas que otras?" (1998, p. 14).

Si como asume el CS, nada puede ser fundamentado al margen de los juegos del lenguaje en los que se inscribe la propia fundamentación ¿cómo es posible optar por un juego del lenguaje determinado para transformar la realidad? Esta posición puede llevarnos a dejar el lugar de la fundamentación ética y política vacío, no ya de fundamentos últimos y trascendentales, sino de cualquier tipo de fundamento parcial e inmanente.

De nuevo, la mirada ontológica binaria implícita en las posiciones socioconstruccionistas nos lleva a un callejón sin salida: tenemos que elegir entre el absolutismo de los fundamentos últimos y las esencias metafísicas o la renuncia a cualquier fundamento utilizando como herramienta política únicamente la problematización y desnaturalización de las objetividades dadas.

Podemos ejemplificar esta posición con estas palabras de Gergen:

La investigación construccionista no va en pos de soluciones para las cuestiones del bien y del mal, sino que más bien se mueve en el sentido de una problematización acrecentada. Resolver los problemas del bien y del mal en cualquier caso en concreto es congelar el significado en un punto dado y por consiguiente, acallar las voces y segmentar el mundo social... En la medida en la que el diálogo sigue y las construcciones continúan abiertas, los significados locales tal vez se ramifiquen y quizá las personas lleguen a compartir o asimilar los modos de vida de los demás. En este resultado descansa tal vez la mayor esperanza de lograr el bienestar humano (1996, p. 50).

Observamos en estas palabras una renuncia a explicitar una posición política concreta (sobre el bien y el mal) para evitar cualquier tipo de fijación ("congelación") que pudiera considerarse como autoritaria por "acallar voces y segmentar el mundo social". Simultáneamente, se propone la problematización y la apertura ¿infinita? de las construcciones sociales. Pero ¿no significa este no-posicionamiento ya una postura muy concreta? Pensamos que sí, en este caso, la que podríamos vincular a una posición liberal-dialógica que confía en la posibilidad de alcanzar el bienestar humano mediante la multiplicación de posiciones en diálogo. La paradoja de esta posición es que se coloca a sí misma en un lugar de exterioridad a las voces y construcciones del mundo social que deben entrar en diálogo; por tanto, en una posición que sí propone una solución "para las cuestiones del bien y del mal"5.

El CS permite desreificar y desconstruir poniendo en evidencia la contingencia de lo social, pero

$5 \quad$ Es preciso dejar claro que ésta no es la única lectura ético-política posible del relativismo epistemológico y del silencio ontológico del CS. Hay otras posiciones, de las que nos encontramos más cerca, como la de lbáñez (2001) quien vincula la necesidad de un compromiso ético y político con una decisión/elección subjetiva. Aún pensamos que la ambigüedad del CS en relación con esta cuestión merece una atención crítica sobre los presupuestos que la sostienen. 
puede resultar inmovilizador por su miedo a reificar el lugar ético-político desde el cual se realiza su crítica. Tal y como hemos argumentado en otro lugar con más detalle, la acción política no consiste solamente en problematizar, deconstruir y politizar el orden de lo dado, sino también en privilegiar y fijar determinadas versiones y posiciones de valor y de poder antes que otras (Ema, García Dauder \& Sandoval, 2003).

Podemos afirmar, por tanto, a modo de síntesis, que los presupuestos epistemológicos, ontológicos y sobre el sujeto del CS nos sitúan ante, al menos, dos tipos de limitaciones para la acción ética y política. La primera tendría que ver con la dificultad de delimitar una posición subjetiva como agente, al tener que elegir entre un sujeto constructor cuasi-omnipotente o un sujeto pasivo, víctima de sus condiciones sociales. La segunda se referiría a la dificultad para ofrecer herramientas que permitan ir más allá de la deconstrucción y la crítica de las objetividades dadas para poder comprometerse con posiciones ético-políticas concretas.

\section{Una ontología materialista y no binaria}

Nuestra propuesta para abordar las cuestiones planteadas pasa por subvertir la modelización binaria de los presupuestos ontológicos implícitos en el CS. Pero ¿qué significa subvertir esta mirada binaria? Desde luego no puede suponer la victoria de alguno de sus polos frente a sus opuestos, sino escapar de la propia lógica-idealista-que los relaciona como mutuamente excluyentes. Podemos definir idealismo como el punto de vista ontológico que reconoce la posibilidad de una metamirada sobre el Todo del ser (o sobre el ser como un todo), de la reducción del ser a una sustancia total, cerrada y suturada, de modo que fuera posible un cierre ontológico bajo algún principio ideal absoluto, ya sea empirista (ej.: los hechos mismos, los objetos del mundo, la realidad "ahí fuera") o racionalista (ej.: un mundo ordenado de acuerdo con leyes...). El idealismo se levanta entonces sobre la misma posibilidad de decir que "todo es". En este sentido, sería igualmente idea- lista aquella posición que afirmara, por ejemplo, que "todo es una construcción social-simbólica" como la que considerara que "todo es material".

$Y$ es que enunciar que "todo es" significa poder ubicarse en un lugar exterior al Todo para poder mirarlo y aprehender sus límites. Así, al analizar el lugar del sujeto que conoce, tanto en el objetivismo positivista como en el CS, podemos encontrar en ambos esta metamirada exterior. En el primer caso, bajo el ideal de la neutralidad y objetividad del "ojo de Dios" (Putnam, 1987), en el segundo, bajo el ideal de una posición subjetiva productora del mundo. La mirada idealista supone, por tanto, un sujeto epistémico desencarnado, separado y abstraído del mundo y, por ello, fuera de su cuerpo, de modo tal que al obviar que el sujeto es corporeizado terminamos por considerar que el sujeto que conoce no es cuerpo, sino mente.

Frente a esta mirada idealista proponemos un punto de vista materialista no reduccionista que NO afirma que "todo es material", sino que renuncia a hablar del mundo en su extensión ya que no podemos afirmar, ni negar, que "todo es". Y no podemos hacerlo precisamente porque también somos mundo y somos construidos en y por él. Así, nuestras construcciones del mundo son en realidad coconstrucciones. No hablamos de agentes constructores por un lado (el sujeto cuasi-omnipotente) y de un mundo construido, por otro, sino del mundo como red compartida de relaciones entre elementos sociales-naturales, humanos y no humanos, de entidades que toman su forma, atributos y significado como resultado de sus relaciones. Así, este privilegio materialista por las relaciones no pone a ningún actor antes de ellas para explicar los procesos de co-construcción de la realidad desde una única fuente y apuesta por una hibridación que escapa de los binarismos ontológicos.

Por tanto, no es posible esa meta-mirada exterior (ni la metamirada del objetivismo, ni la de sujeto cuasi-omnipotente del CS). Y es que, retomando la expresión de Jacques Lacan (1981) la realidad es "no-toda", es decir, no puede formar una totalidad (Copjec, 2006a). De este modo podríamos afirmar junto con el CS que no existe realidad que no esté mediada por nuestras construcciones 
simbólico culturales pero distanciándonos de él simultáneamente que no todo en la realidad es simbólico cultural'. Esta doble enunciación nada afirma sobre la totalidad, sobre la posibilidad de capturar la realidad bajo alguna definición total. Pero también nos señala cómo la realidad no se puede reducir a un efecto de construcción social, hay algo que dificulta y limita la omnipotencia de lo social-cultural. Este "algo" limitante no es una supuesta realidad positiva y exterior al discurso (a nuestras relaciones y prácticas socio-simbólicas - una naturaleza sustantiva, esencial y plena del mundo, por ejemplo-) sino algo inherente a ellas: la misma imposibilidad del discurso de decirlo todo, la propia imposibilidad de la razón humana de aprehender el Todo. $Y$ es que con el discurso y la razón siempre fallamos, nunca alcanzamos a representar nuestra existencia como plenitud. Pero precisamente nuestra vida es posible gracias a este fallo, hablamos y razonamos para poder manejarnos con esta imposibilidad inherente a nuestra condición humana.

A partir del reconocimiento de esta dimensión imposible, podemos terminar de caracterizar nuestra propuesta mediante las siguientes palabras de Slavoj Žižek: "La realidad que veo nunca es 'total', no porque una parte importante me elu$\mathrm{da}$, sino porque contiene una mancha, un punto ciego, que señala mi inclusión en ella" (2006, p. 26). Encontramos en este enunciado los principales elementos ontológicos y epistemológicos que constituyen nuestro punto de vista materialista.

Por una parte tenemos, de modo similar a las posiciones socioconstruccionistas: (1) una mirada no-esencialista (el mundo es incompleto, no hay posibilidad de plenitud, no es posible una realidad total); (2) un distanciamiento del punto de vista objetivo-positivista que considera un mundo "ahí fuera", independiente de nuestro modo de conocer (la realidad no elude mi conocimiento); y (3) una vinculación implícita entre conocimiento y ontología, puesto que la realidad no es independiente de nuestro modo de conocer (hay algo de

6 Esta lectura materialista desarrollada a partir de esta lógica del "notodo" está basada en las ideas de Joan Copjec y Slavoj Žižek y en la vinculación que establecen entre las antinomias cosmológicas de la razón de Kant y el "lado" femenino de las fórmulas lacanianas de la sexuación (Copjec, 2006b; Žižek, 2006, 2004a, 2003). nuestra mirada sobre la realidad que está en la realidad misma, al menos, una mancha).

Sin embargo, podemos observar también algunas diferencias relevantes con el Construccionismo Social (CS):

1.- Para el CS el modo como el sujeto (mediante el conocimiento) construye el objeto es, podríamos decir, aditivo-productivo, es decir, el objeto se constituye con algo que se pone, se añade-produce, desde el lado de lo humano. Sin embargo, para la posición materialista que sostenemos, lo que el sujeto - lo humano- aporta es también una sustracción: la imposibilidad de una presencia plena. A esta imposibilidad se refiere Žižek al reconocer un punto ciego en la realidad que nos impide verla como totalidad. No se trata de que haya una realidad más allá que no podamos ver (una parte importante de la realidad que me eluda) sino que es nuestra misma inclusión en ella la que hace imposible una realidad ahí fuera como totalidad independiente de nosotros. Es decir, la incompletud de la realidad es correlativa a la inserción material del sujeto en el mundo y a la imposibilidad de la razón, del lenguaje y del conocimiento de aprehender el Todo. Es la misma razón humana la que hace imposible un "todo del ser” pero no (sólo) como una limitación de la misma razón y el conocimiento, sino como "una propiedad del ser" (Copjec, 2006a).

2.- Esta interdependencia "sustractiva" entre los límites del conocimiento y la incompletud de la realidad nos sitúan ante un modo de entender las relaciones entre epistemología y ontología alternativa a la socioconstrucionista. La relación entre el conocimiento y su objeto es tan íntima, a partir de sus limitaciones, que sitúa a ambos en una situación de estrecha interdependencia que nunca es reconciliada (por ejemplo, bajo un conocimiento "definitivo" del mundo o de nosotros mismos). Sujeto, conocimiento y objeto están íntimamente vinculados, hasta el punto de que "un desplazamiento 'epistemológico' en el punto de vista del sujeto refleja siempre un desplazamiento 'ontológico’ en el objeto mismo” (Žižek, 2006, p. 25). No se trata de reabsorber la ontología en la epistemología - tal y como hace el CS con su silencio 
ontológico (no podemos decir nada sobre la naturaleza del objeto sólo cómo lo conocemos) - sino de mantener una cierta brecha insuperable pero interdependiente entre nuestro conocimiento y lo que el objeto es (imposible, incompleto, no definitivo y por tanto no alcanzable como una totalidad por nuestra mirada).

Como puede apreciarse no hay aquí recuperación de esencia metafísica alguna y, sin embargo, los presupuestos ontológicos (el ser, la realidad como imposible, incompleta, etc.) no quedan desdibujados bajo un silencio ontológico.

3.- Por último, esta interdependencia entre epistemología y ontología $-\mathrm{y}$ entre sujeto y objeto, mediante el conocimiento- es finalmente de doble dirección y pone de manifiesto que mediante el conocimiento se construye realidad, pero también al propio sujeto.

La mirada del sujeto está inscrita en el mundo y, por tanto, es constitutiva de lo que el mundo es para el sujeto. Pero, si el sujeto pudiera distinguir lo que hay de él en la realidad (su mirada inscrita en ella) $-y$, por tanto, lo que la realidad es sin su mirada-sí sería posible un punto de vista objetivo-positivista sobre el mundo "ahí fuera". Eso es lo que el "método científico" ha tratado de hacer: depurar el método de conocimiento hasta sacar cualquier elemento ("sesgo") subjetivo presente en el objeto. Sin embargo, tal depuración no es posible. El objeto devuelve la propia mirada del sujeto a éste y esta mirada devuelta forma parte de lo que el sujeto percibe como realidad. Sin embargo, la mirada devuelta no puede ser aprehendida por el sujeto, no puede ser vista por él (Lacan, 1987). Por eso ese punto desde el cual el objeto devuelve la mirada al sujeto supone para él una "mancha", un "punto ciego", en su propia visión.

Y esta mancha permite un doble movimiento. Por una parte, indica precisamente el lugar de nuestra inserción material en el mundo. El punto en el cual somos también mundo y formamos parte del cuadro que estamos contemplando. Pero por otra, permite la aparición de una distancia necesaria entre sujeto y mundo. Necesaria para que el conocimiento sea posible y el sujeto pueda percibirse como separado del objeto. Pero además, no sólo el objeto es constituido por el sujeto como algo separado de él, sino que también la propia mirada que nos devuelve el objeto es constitutiva de nuestra posición subjetiva (que nunca será la posición de un sujeto completo, definitivo, sino atravesado por esa mirada de "lo otro" imposible de capturar ${ }^{7}$ ).

Tenemos experiencia de esto cuando observamos, por ejemplo, cómo nuestros "prejuicios" ideológicos lejos de imposibilitar una mirada sobre la verdadera realidad del mundo, son precisamente la condición de posibilidad de nuestra mirada "objetiva” sobre él. Estos "prejuicios" son nuestra propia mirada devuelta y ocultada que aparecen, no como una condición subjetiva de nuestra mirada sino como una propiedad específica del objeto, es decir, bajo la misma forma de la objetividad. De este modo introducimos una cierta distancia entre sujeto y mundo (justo a partir de este "punto ciego" en nuestra mirada) que nos permite constituirnos como sujetos separados de los objetos.

Nótese cómo en esta lectura materialista conviven simultáneamente, por tanto: La posibilidad de una distancia entre sujeto y objeto (sin esta distancia, no habría ni sujeto, ni mundo, ni conocimiento) y la misma constitución del sujeto íntimamente situado y atrapado en el mundo. Podemos pensar, por tanto, en los elementos mediadores de nuestro conocimiento (es decir, todos aquellos elementos que nos vinculan con el mundo y simultáneamente nos permiten establecer una distancia con él: desde los terminales nerviosos a los códigos simbólico-culturales) como un resultado de nuestra articulación situada en el

$7 \quad$ Nuestra posición subjetiva se constituye intersubjetivamente a partir de la mirada del otro, tal y como ya se sabe bien en la psicología social. Pero esta mirada (del otro humano o no humano) no es absolutamente transparente para nosotros, de modo que a nuestra interdependencia (de la mirada) del otro tenemos que añadir la dimensión afectiva y deseante que implica ser (bien) reconocidos por esa mirada y reconocernos en ella. Por eso debemos complejizar el punto de vista "reflexivo" sobre la acción humana que proponen enfoques como el Interaccionismo Simbólico (por ejemplo en Mead, 1977), incorporando esta dimensión afectiva -que es limitante de la misma posibilidad de un conocimiento transparente de los otros y autotransparente de uno mismo-. 
mundo (son también mundo) y no (sólo) una condición individual o subjetiva del conocimiento ${ }^{8}$.

En resumen, el punto de vista materialista no significa únicamente la afirmación directa de mi inclusión en la realidad objetiva (Žižek, 2006) sino que supone un movimiento de dos direcciones (sujeto-objeto y viceversa) que, a la vez que da testimonio de mi existencia material y situada en el mundo, constituye el mismo mundo en donde estoy incluido. Por eso, inherente a nuestras prácticas de conocimiento, podemos reconocer una dimensión de subjetivación.

El conocimiento supone, por tanto, un triple movimiento simultáneo y mutuamente dependiente: (1) una representación del mundo (habilitada por la creación de una distancia entre el mundo y objeto); (2) la producción de un objeto como algo diferente del sujeto; y (3) la propia producción de un sujeto (separado del objeto). Este triple proceso es precisamente el correlato de la imposibilidad del mundo coherente, absolutamente separado de nosotros. El mundo es imposible de percibir como un todo cerrado, precisamente porque, en tanto sujetos que conocemos, estamos insertados en el mundo mismo formando parte de él.

\section{A modo de conclusión: un sujeto-agente responsable y un conocimiento situado}

Llegados a este punto, terminamos por hilvanar los argumentos expuestos para mostrar las implicaciones ético-políticas de la mirada materialista que hemos presentado. En nuestra opinión, este punto de vista ontológico (y sus implicaciones sobre el sujeto y el conocimiento) son una condición

8 Puede reconocerse en este punto el parecido de familia con el enfoque enactivo del biólogo y epistemólogo Francisco Varela. Para este autor: "Estamos obligados a concluir que la cognición no se puede entender adecuadamente sin sentido común, el cual no es otra cosa que nuestra historia corporal y social, la inevitable conclusión es que conocedor y conocido, sujeto y objeto, se determinan uno al otro y surgen simultáneamente" (1988, p. 96). Así, entiende por cognición: "hacer emerger un mundo" mediante el acoplamiento de las entidades implicadas. Varela propone la enacción como proceso de articulación entre sujeto y objeto destacando cómo las propiedades de ambos son emergentes en la relación: "lo que marca la diferencia entre el enfoque enactivo y cualquier forma de constructivismo o neokantismo biológico es este énfasis en la codeterminación" (1988, p.102). ineludible para pensar las prácticas emancipadoras hoy en día. Acercarnos al conocimiento científico en las ciencias sociales desde esta mirada supone admitir la imposibilidad de una mirada determinista sobre el comportamiento humano bajo alguna ley o causa universal. $Y$ ello, no tanto porque nuestro comportamiento no esté regulado y normativizado, sino porque las propias leyes reguladoras son finalmente la sedimentación de los intentos reiterados por domesticar la imposibilidad inherente a la existencia humana (intentos que no consiguen alcanzar definitivamente su objetivo). Esto se puede confirmar con el siguiente argumento de Alemán:

La lengua, el sexo, la muerte nombran el mismo exilio, la misma imposibilidad; jamás podrá ser conquistada una identidad plena ni por la reflexión de la conciencia, ni por el dominio del yo, ni por el "autocontrol", ni por el proceso de emancipación. La existencia siempre construye su casa o refugio desde el temblor de las huellas de lo imposible... nombran entonces la misma imposibilidad, la de establecer una relación "sustancial", permanente, "natural”, con la vida (p. 24).

Vivimos íntimamente atrapados en el mundo, somos resultado de una trama de relaciones que nos precede. Pero simultáneamente el mundo es también humano-dependiente, tal y como ha puesto de manifiesto el CS. No hay exterioridad entre mundo y sujeto. Por tanto, mundo y sujeto no se relacionan como entidades completas y separadas, sino como articulaciones a partir de la imposibilidad de un mundo cerrado y de un sujeto definitivo y pleno'. Tal y como hemos puesto de manifiesto, esta imposibilidad es ontológica, no se trata (sólo) de una limitación epistemológica. Por esta razón, nuestras prácticas de conocimiento -es decir, las mismas prácticas mediante las que el mundo es constituido como objetividad (para nosotros) - son simultáneamente prácticas

9 Este sujeto incompleto no se relaciona con el mundo como un reducto de intimidad separado de un escenario exterior. En realidad, la propia intimidad del sujeto es ya extimidad en relación con el mundo. Con este neologismo tomado de Lacan (1989) nos escapamos de la oposición limitante entre mundo interno y mundo externo para poner de manifiesto que el sujeto está habilitado (y limitado) por algo extranjero y ajeno, la alteridad radical de "lo otro" que viene de afuera y su correlato en lo más íntimo y desconocido en cada uno. 
de subjetivación, de producción de un sujeto. Por ello y junto con ello, el mundo se constituye como objetividad en la medida en la que se incluye en él al propio sujeto.

Y esto lo cambia todo. Ya no podemos entender el conocimiento como un proceso cognitivo neutral que circula entre sujeto y mundo, sino como un momento constitutivo de sujeto y mundo que conlleva una marca subjetiva de la que podemos/ debemos hacernos cargo. De este modo, el criterio de legitimidad del conocimiento ya no será su correspondencia con la realidad "ahí fuera", sino también el de la responsabilidad derivada de nuestro papel (situado, limitado) como co-constructores del mundo, es decir, con nuestra propia posición subjetiva en el mundo.

Es preciso distanciarse aquí de cualquier lectura idealista de esta noción de responsabilidad que estamos proponiendo. No se trata de recuperar un antropocentrismo humanista que pondría al sujeto en el centro de todo, sino precisamente de hacernos cargo de nuestra posición incompleta y de interdependencia, de cómo nuestra capacidad de acción siempre es derivada de nuestra interacción con otros (incluso con otros no humanos). Así, lejos de toda pretensión de omnipotencia, se trata de manejarnos con los límites de nuestra (im)potencia constatando que no es posible una mirada transparente sobre nosotros mismos y sobre el mundo, y que nuestro conocimiento objetivo es inherentemente parcial y situado, y se sostiene en la misma imposibilidad de una metamirada sobre el Todo.

Esta posibilidad de un sujeto-agente responsable no puede venir del lado de un sujeto calculable bajo cualquier ley -social, biológica, u otras-, pero tampoco del de un sujeto completamente por encima de la Ley como actor/legislador omnipotente. Es decir, un sujeto-agente responsable, no puede estar ni por encima -un sujeto omnipotente-, ni por debajo de la ley -un sujeto calculable-. Este sujeto, radicalmente incognoscible e incalculable, es la única garantía que tenemos para la ética y la política. Esta garantía es, por tanto, la misma imposibilidad de un cierre definitivo (idealista) por encima o por debajo del trasfondo de regularidades y relaciones de poder en el que habitamos. La propia incompletud del sujeto derivada de su inserción material y simbólica en el mundo es la que precisamente lo habilita como sujeto ético. En la medida en que este sujeto no las tiene todas consigo - no tiene un fundamento último del qué deducir su acción algorítmicamente- se ve confrontado con la dimensión indecidible $^{10}$ inherente a la ética y la política (Ema, 2007).

Por eso esta responsabilidad a la que apelamos es materialmente situada, es "no-toda" (Žižek, 2004b). No consistiría en afirmar: soy responsable de todo, sino más bien: no existe nada a lo que no pueda vincular mi responsabilidad y simultáneamente: no soy responsable de todo (no puedo tener una visión global del Todo). Estar arrojado al mundo, condicionado, limitado pero habilitado en él, significa que no hay nada que pueda escapar a una mirada responsable, aunque ésta, como el mundo, sea no-toda. Pero también asumir modestamente nuestra imposibilidad de hacernos cargo de todo, abandonar el trono del ideal del Sujeto dominador de la Naturaleza y de la propia naturaleza humana.

Desde este punto de vista, no renunciaríamos al uso del término objetividad como criterio de legitimidad del conocimiento si vinculamos ésta a la noción de responsabilidad que hemos presentado. Así, podemos poner la objetividad de nuestros conocimientos en función de su subordinación a un saber práctico que nos permita articular significados y representaciones para mostrar, en relación con la cuestión que nos ocupa, un horizonte posible de cambio emancipador. En este sentido, tal y como afirma Haraway:

lo imaginario y lo racional -la visión visionaria y objetiva- rondan juntos (...) este toque cercano del elemento fantástico de esperanza

10 Derrida define lo indecidible en su reflexión sobre la justicia de una decisión que siguiendo una regla general debe enfrentarse a la singularidad de una situación concreta y única, del siguiente modo: Lo indecidible no es meramente la oscilación o la tensión entre dos decisiones; es la experiencia de aquello que, aunque heterogéneo, extraño al orden de lo calculable y de la regla, aun está obligado -es de obligación de lo que debemos hablar- a rendirse a la decisión imposible, a la vez que toma en cuenta la ley y las reglas. Una decisión que no pasará a través de la dura prueba de lo indecidible no sería una decisión libre, sería solamente la aplicación o el despliegue programable de un proceso calculable (Derrida, 1997, p. 57). 
en el conocimiento transformador y la severa verificación y el estímulo de la búsqueda crítica sostenida, son la base de cualquier pretensión creíble de objetividad o de racionalidad, no cargada de negaciones desalentadoras y de represiones desalentadoras (1995, p. 330).

Por eso, el problema ético y político de la objetividad del conocimiento no es tanto el de la fidelidad de la representación, sino, más bien, el de su fiabilidad y validez para la transformación emancipadora. Es decir, de su capacidad de articular experiencias y prácticas concretas y desde ellas contribuir al impulso de la acción etico-política. Sostenemos así un criterio de verdad del conocimiento pragmático y éticamente situado, y no el de la neutralidad abstracta, y finalmente imposible, de la correspondencia con la "realidad ahí fuera" tal y como nos prometió el objetivismo positivista.

El CS, articulado con toda una serie de propuestas críticas, nos ha permitido a lo largo de estos años problematizar algunos presupuestos epistemológicos y ontológicos que sostenían y sostienen las prácticas normativizadoras de las ciencias sociales y especialmente de la psicología. En este trabajo hemos tratado de prolongar su impulso crítico radicalizando, matizando o apartándonos de algunas de sus principales herramientas. De cualquier modo, la tarea crítica no puede terminar, no hay un lugar seguro para su descanso. La disposición para la crítica debe permanecer siempre abierta, hasta para deshacer sus propios cimientos.

\section{Referencias}

Abril, G. (1999). Cronotopías del destiempo. Viajes a los cronotopos sociales y textuales de la sociedad de la información y a sus astucias. En Gatti, G. \& Martínez de Albeniz, I. (Coords). Las astucias de la identidad: Figuras, territorios y estrategias de lo social contemporáneo. Bilbao: UPV/EHU

Agamben, G. (1996). La comunidad que viene. Valencia: Pre-textos.
Alemán, J. (2003). Derivas del discurso capitalista: notas sobre psicoanálisis y política. Málaga: Miguel Gómez Ediciones.

Alemán, J. (2003). Existencia y sexo: notas sobre el psicoanálisis. Recuperado el día 3 de julio de 2005 de: http://www.hartza.com/sexistencia.html.

Burr, V. (1998). Overview: realism, relativism, social constructionism and discourse. En Parker, I. (comp.). Social Constructionism, Discourse and Realism. Londres: Sage Publication.

Copjec, J. (2006a). Imaginemos que la mujer no existe. Ética y sublimación. Buenos Aires: Fondo de Cultura Económica.

Copjec, J. (2006b). El sexo y la eutanasia de la razón. Ensayos sobre el amor y la diferencia. Buenos Aires: Paidós.

Derrida, J. (1997). Fuerza de ley. El fundamento místico de la autoridad. Madrid: Tecnos.

Ema López, J. E., García D. S. \& Sandoval Moya, J. (2003). Fijaciones políticas y trasfondo de la acción: movimientos dentro/fuera del socioconstruccionismo. Política y Sociedad, 40 (1), 71-86. Recuperado el 19 de diciembre de 2007 desde http://www.ucm.es/BUCM/revistasBUC/portal/abrir.php?url=http://www. ucm.es/BUCM/revistas/cps/11308001/articulos/POSO0303130071A.PDF.

Ema López, J. E. (2004). Del sujeto a la agencia (a través de la política). Athenea Digital, 5. Recuperado el 12 de enero de 2005 desde: http://psicologiasocial.uab.es/athenea/index.php/atheneaDigital/article/view/114/114

Ema López, J. E. (2007). Lo político, la política y el acontecimiento. Foro interno: anuario de teoría política, 7, 51-76. Recuperado el 19 de diciembre de 2007 desde http://www.ucm.es/BUCM/ revistasBUC/portal/abrir.php?url=http://www. ucm.es/BUCM/revistas/cps/15784576/articulos/FOIN0707110051A.PDF. 
Gergen, K. (1985). The Social Constructionist Movement in Modern Psychology. American Psychologist, 40, 266-275.

Gergen, K. (1996). Realidades y relaciones. Aproximaciones a la construcción social. Barcelona: Paidós.

Gergen, K. (1999). A Invitation to Social Construction. Londres: Sage.

Haraway, D. (1995). Ciencia, cyborgs y mujeres. La reinvención de la naturaleza. Madrid: Cátedra.

Ibáñez, T. (1994). Psicología Social Construccionista. Guadalajara: Universidad de Guadalajara.

Ibáñez, T. (1996). Construccionismo y psicología. En Gordo López, A. \& Linaza, J.L. (comp.). Psicologías, discursos y poder. Madrid: Visor.

Ibáñez, T. (2001). Municiones para disidentes. Realidad-verdad-política. Barcelona: Gedisa.

Lacan, J. (1981). El Seminario de Lacan. Libro 20. Aun. 1971-1973. Buenos Aires: Paidós.

Lacan, J. (1987). El Seminario de Lacan. Libro 11. Los cuatro conceptos fundamentales del Psicoanálisis. 1964. Buenos Aires: Paidós.

Lacan, J. (1989). El Seminario de Lacan. Libro 7. La ética del psicoanálisis. 1959-1960. Buenos Aires: Paidós.

Latour, B. (1992). Ciencia en acción. Barcelona: Labor.

Latour, B. (1993). Nunca hemos sido modernos. Madrid: Debate.

Mead, G. H. (1977). Espíritu, persona y sociedad. Barcelona: Paidós.
Pujal i Llombart, M. (2003). La tarea crítica: interconexiones entre lenguaje, deseo y subjetividad. Política y sociedad, 40 (1), 129-140. Recuperado el 19 de diciembre de 2007 desde http://www.ucm.es/BUCM/revistasBUC/ portal/abrir.php?url=http://www.ucm.es/ BUCM/revistas/cps/11308001/articulos/POSO0303130129A.PDF.

Pujol, J., Montenegro, M. \& Balasch, M. (2003). Los límites de la metáfora lingüística: implicaciones de una perspectiva corporeizada para la práctica investigadora e interventora. Política y Sociedad, 40 (1), 57-70. Recuperado el 19 de diciembre de 2007 desde http://www.ucm.es/BUCM/ revistasBUC/portal/abrir.php?url=http://www. ucm.es/BUCM/revistas/cps/11308001/articulos/ POSO0303130057A.PDF.

Putnam, H. (1987). Las mil caras del realismo. Barcelona: Paidós.

Rorty, R. (1979). La filosofía y el espejo de la naturaleza. Madrid: Cátedra.

Sandoval, J. (2004). Representación discursividad y acción situada. Valparaíso: Universidad de Valparaíso.

Varela, F. (1988). Conocer. Barcelona: Gedisa.

Žižek, S. (2003). Las metástasis del goce. Seis ensayos sobre la mujer y la causalidad. Buenos Aires: Paidós.

Žižek, S. (2004a). A propósito de Lenin. Política y subjetividad en el capitalismo tardío. Buenos Aires: Atuel.

Žižek, S. (2004b). Violencia en acto. Conferencias en Buenos Aires. Buenos Aires: Paidós.

Žižek, S. (2006). Visión de paralaje. Buenos Aires: Fondo de Cultura Económica. 